\title{
Partnering with diabetes educators to improve patient outcomes
}

This article was published in the following Dove Press journal:

Diabetes, Metabolic Syndrome and Obesity:Targets and Therapy

12 February 2014

Number of times this article has been viewed

\section{Sandra D Burke ${ }^{1,2}$ \\ Dawn Sherr ${ }^{3}$ \\ Ruth D Lipman ${ }^{3}$}

'American Association of Diabetes Educators, Chicago, IL, USA; ${ }^{2}$ University of Illinois at Chicago College of Nursing, Urbana, IL, USA; ${ }^{3}$ Science and Practice, American Association of Diabetes Educators, Chicago, IL, USA
Correspondence: Sandra D Burke University of Illinois at Chicago College of Nursing, 845 South Damen Avenue, MC 802, Chicago, IL 60612, USA

Tel +I 2173332507

Email sdburke@illinois.edu
Abstract: Diabetes is a chronic, progressive disease that affects millions worldwide. The paradigm of diabetes management has shifted to focus on empowering the person with diabetes to manage the disease successfully and to improve their quality of life. Diabetes self-management education is a collaborative process through which people with diabetes gain the knowledge and skills needed to modify their behavior and to self-manage successfully the disease and its related conditions. Diabetes educators are health care professionals who apply in-depth knowledge and skills in the biological and social sciences, communication, counseling, and pedagogy to enable patients to manage daily and future challenges. Diabetes educators are integral in providing individualized education and promoting behavior change, using a framework of seven self-care behaviors known as the AADE7 Self-Care Behaviors ${ }^{\mathrm{TM}}$, developed by the American Association of Diabetes Educators. The iterative process of promoting behavior change includes assessment, goal setting, planning, implementation, evaluation, and documentation. Diabetes educators work as part of the patient's health care team to engage with the patient in informed, shared decision making. The increasing prevalence of diabetes and the growing focus on its prevention require strategies for providing people with knowledge, skills, and strategies they need and can use. The diabetes educator is the logical facilitator of change. Access to diabetes education is critically important; incorporating diabetes educators into more and varied practice settings will serve to improve clinical and quality of life outcomes for persons with diabetes.

Keywords: diabetes educator, diabetes self-management education, healthcare team, behavior change

\section{Introduction}

One in every three Americans currently has or is at risk to develop diabetes mellitus. ${ }^{1}$ Worldwide, the number of individuals with diabetes is growing at an unprecedented rate and is expected to surpass 550 million by $2030 .^{2}$ Diabetes mellitus (diabetes) is actually a group of diseases characterized by high blood glucose levels that result from defects in the body's ability to produce and/or use insulin. The hyperglycemia resulting from the excessive amounts of circulating glucose can be aggravated by exogenous factors, such as food consumption, physical activity, inflammation, medications, and stress. The chronic, progressive nature of diabetes necessitates ongoing medical care; it benefits from timely access to patient self-management education and support to prevent acute complications and to reduce the risk of long-term complications. ${ }^{3}$ Adequately responding to and managing circulating glucose requires an assortment of elements, including an ongoing assessment of pharmacology, nutritional interventions, and monitoring. 
Historically, diabetes was depicted as a condition managed by diet, exercise, and medication. Seemingly straightforward, diabetes management has always been challenging. Changes in each of these treatment elements over the past 2 decades have increased the overall complexity of the disease's management.

Nutritional intake remains the foundation of diabetes management. However, the diabetes diet has shifted away from a physician-prescribed, calorie-restricted exchange diet toward an individualized meal plan that takes into account a patient's cultural background and nutritional likes and dislikes. Exercise, which is still widely recognized as an anchor to diabetes management, is now carefully linked to the patient's routine so as to maximize the effect of physical activity while minimizing the risk of hypoglycemia. Dealing with the next anchor, medication management, has become an art form in recent times. Myriad new medications, each with unique characteristics, benefits, and side effects, have joined insulin and the oral sulfonylureas in the vast array of available antihyperglycemic agents. Monitoring once referred only to the occasional capillary and random plasma glucose test and periodic glycated hemoglobin (A1C) measurements. Now, it includes routine self-monitoring of blood glucose and blood pressure, as well as the scheduled clinical assessment of the A1C, lipid levels, and kidney function tests. Added to routine metabolic measurements is the monitoring of weight, body mass index, waist circumference, examination of eyes and feet, and assessment of quality of life.

Although uncontrolled diabetes continues to be associated with major vascular complications, studies in the US and abroad have demonstrated that improved glycemic control benefits people with either type 1 or type 2 diabetes. ${ }^{4-6}$ While the absolute difference in risk of complications may vary for certain subgroups of people, ${ }^{1}$ in general, every percentage point drop in A1C blood test results (eg, from 8.0\%-7.0\%) reduces the risk of microvascular complications (eye, kidney, and nerve diseases) by $40 \% .{ }^{4}$ It has been said that the expected benefits from diabetes treatment, such as the reductions in risk of diabetic eye disease, kidney disease, or heart disease, may take many years to become apparent. ${ }^{7}$ However, results from the ongoing Diabetes Control and Complications Trial/ Epidemiology of Diabetes Interventions and Complications (DCCT/EDIC) clearly demonstrate that early and sustained glucose control has lasting impact. ${ }^{8-11}$ Diabetes management is not a simple undertaking. Effective diabetes management requires more than a knowledgeable clinician. It should also include the incorporation of a strong and focused health care team with all team members - including the patient - sharing the decision making. The focus should be to engage the person with diabetes in his or her own care. ${ }^{12}$

Therefore, based on the most current evidence, it is essential to assist people with diabetes in obtaining the knowledge, skills, and abilities required for effective, sustained selfmanagement of their condition. The purpose of this paper is to outline the aspects involved in comprehensive and ongoing diabetes education and support and to demonstrate the efficacy of partnership with a credentialed diabetes educator.

\section{Shifting paradigm}

Managing diabetes requires a concerted effort on the part of the patient. A wide body of evidence now demonstrates that knowledge alone is insufficient to promote behavior change. ${ }^{13,14}$ Management of a chronic condition, such as diabetes, requires engaging the individual to take an active role in self-care. At diagnosis, symptomatic patients may be motivated to control their disease to alleviate the symptoms. While symptoms are common in the patient with new onset type 1 diabetes, early diagnosis in someone with type 2 diabetes may be met with skepticism, as there are no symptoms until hyperglycemia is well over the renal threshold of $180 \mathrm{mg} / \mathrm{dL}$. Given the absence of symptoms, motivation to self-manage may not be as popular, or as common, at this stage of the illness.

Education is an essential element of self-management. However, the transfer of information from the health care professional to the person with diabetes represents only the beginning of a lifelong process leading to successful self-care. Motivating someone to take control of a chronic disease requires a unique skill set as well as more time than is typical in a standard health care visit. Indeed, empowering the person with diabetes to be an active participant in his or her care requires a shift away from the traditional, acute-care model of health care delivery common to the US. ${ }^{15-17}$ Beyond providing general knowledge of diabetes care, for selfmanagement to be effective, it is essential to tailor both the treatment and the education to the needs of the individual. In this era of evidence-based practice, it is important to provide patient-centered care, which has been defined by the Institute of Medicine as care that respects the individual's preferences and values and incorporates shared decision making. ${ }^{18}$

The centrality of the person with diabetes has long been a fundamental tenet of the American Association of Diabetes Educators (AADE) code of ethics, and it is a principle that is captured in the AADE position statement on the "Individualization of diabetes self-management education."19 In recent years, this focus on individualizing education and 
treatment has gained traction among other health care providers, as evidenced by recent consensus statements about target glucose levels and with clinical practice guidelines and practice recommendations now being less prescriptive and less algorithmic. ${ }^{20,21}$ Importantly, even when diabetes treatment is tailored specifically to meet the needs of the individual, successful self-management depends on the commitment of that individual. To deal with the complexities of day-to-day diabetes, the individual with this disease must not only have core knowledge, but he or she must also possess the skills, abilities, and motivation for self-management.

\section{Defining diabetes self-management education}

In the recent past, it has become clear that patients who do not receive formal diabetes self-management education (DSME) have knowledge gaps, tend not to receive recommended preventive services, and are more likely to develop chronic complications than those who have received DSME. ${ }^{22,23}$ DSME is an interactive, collaborative, and ongoing process through which people with or at risk for diabetes gain the knowledge and skills needed to modify behavior and successfully self-manage the disease and its related conditions. The process of DSME incorporates the individual's needs, goals, and life experiences, and is guided by evidence-based standards. The overall objectives of DSME are to support informed decision making, self-care behaviors, problem solving, and active collaboration with the health care team and to improve clinical outcomes, health status, and quality of life. ${ }^{24}$ In short, these are educational interventions designed to help persons with diabetes achieve an optimal health status and an improved quality of life, while reducing the need for costly health care.

The fundamental outcome of DSME is behavior change. ${ }^{25}$ This outcome can be attained using a six-step process that includes assessment, goal setting, planning, implementation, evaluation, and documentation. ${ }^{26}$ Each step of the process is important.

First, similar to any health care encounter, every visit begins with the assessment. To design and implement an effective, individualized DSME program, the initial assessment must be comprehensive and must include all aspects related to diabetes management and self-care. The comprehensive history goes beyond collecting information about diabetes-related physical symptoms and objective clinical data. This history hones in on personal lifestyle factors, such as daily routine, eating patterns, tobacco and alcohol use, exercise habits, living arrangements, type of occupation, and/or financial barriers to self-management. Mental health status, psychosocial concerns, functional and health literacy, health beliefs, typical approaches to problem solving - as well as readiness for and barriers to learning - are also included. Because many of these attributes are dynamic, the assessment needs to be an ongoing component of the process. An effective way to conduct the assessment specific to diabetes self-management is to use the AADE7TM framework. This evidenced-based framework was developed more than a decade ago as diabetes education moved from a content-driven model to an outcomes-driven model. ${ }^{25,27,28}$ Since its inception, the AADE7 ${ }^{\text {TM }}$ framework has become an iconic tool, useful not only within the diabetes community, but also with many other chronic disease processes. The AADE7TM framework consists of seven factors essential for self-management: healthy eating, physical activity, taking medications, monitoring, problem solving (related to diabetes self-care), reducing risks of acute and chronic complications, and psychosocial aspects of living with diabetes. An explanation of each element of the AADE7TM is provided in Table 1. Subsequent assessments, as well as educational content, can be focused on one or more areas of the AADE7TM , depending on the individual's existing goals.

Second, goal setting, the next step in the process, follows assessment (and reassessment). Several areas of concern are likely to flow from the assessment. Certainly, goal setting is not a skill that is restricted to diabetes self-management. ${ }^{29}$ However, in an empowerment-driven model, the clinician does not set goals for the patient. Rather, in the context of the DSME, the clinician guides the individual as he or she chooses an area of focus (healthy eating, activity, etc) and then - working together - they establish specific, measurable, attainable, realistic, and timely (SMART) goals. ${ }^{30}$ Goal setting is an iterative process that often begins with goals that are easy to achieve in the short-term. As the individual works through the process and learns to independently set SMART goals, the areas of focus may expand. Goal setting, in and of itself, is a valuable skill that assists the person with problem solving on a daily basis.

Third, the diabetes educator guides the individual to develop a specific plan. The plan involves forming concrete strategies aimed at achieving the goals established during the goal setting process. Planning gives the individual a road map to follow. Multiple steps may be needed to accomplish the individual's goals. Importantly, plans must take into account that daily management is difficult and imperfect. In other words, the individual may have difficulty following the plan every day. Depending on the focal area of the goal, the 
Table I AADE7 Self-Care Behavior Definitions ${ }^{\mathrm{TM}}$

Healthy eating: Making healthy food choices, understanding portion sizes and learning the best times to eat are central to managing diabetes. By making appropriate food selections, children and teenagers grow and develop as they would if they didn't have diabetes. And, by controlling their weight, many adults may be able to manage their condition for a time without medications.

Diabetes self-management education and training classes can assist people with diabetes in gaining knowledge about the effect of food on blood glucose, sources of carbohydrates and fat, appropriate meal planning and resources to assist in making food choices. Skills taught include reading labels, planning and preparing meals, measuring foods for portion control, fat control and carbohydrate counting. Barriers, such as environmental triggers and emotional, financial, and cultural factors, are also addressed.

Being active: Regular activity is important for overall fitness, weight management and blood glucose control. With appropriate levels of exercise, those at risk for type 2 diabetes can reduce that risk, and those with diabetes can improve glycemic control. Being active can also help improve body mass index, enhance weight loss, help control lipids and blood pressure, and reduce stress.

Diabetes educators and their patients collaborate to address barriers, such as physical, environmental, psychological, and time limitations. They also work together to develop an appropriate activity plan that balances food and medication with the activity level.

Monitoring: Daily self-monitoring of blood glucose provides people with diabetes the information they need to assess how food, physical activity, and medications affect their blood glucose levels. Monitoring, however, doesn't stop there. People with diabetes also need to regularly check their blood pressure, urine ketones, and weight.

Diabetes self-management education and training classes instruct patients about equipment choice and selection, timing and frequency of testing, target values, and interpretation and use of results.

Taking medication: Diabetes is a progressive condition. Depending on what type of diabetes a person has, their health care team will be able to determine which medications they should be taking and help them understand how their medications work. For example, they can demonstrate how to inject insulin or explain how diabetes pills work and when to take them. Effective drug therapy in combination with healthy lifestyle choices, can lower blood glucose levels, reduce the risk for diabetes complications, and produce other clinical benefits.

The goal is for the patient to be knowledgeable about each medication, including its action, side effects, efficacy, toxicity, prescribed dosage, appropriate timing and frequency of administration, effect of missed and delayed doses, and instructions for storage, travel, and safety.

Problem solving: A person with diabetes must keep their problem-solving skills sharp because on any given day, a high or low blood glucose episode or a sick day will require them to make rapid, informed decisions about food, activity, and medications. This skill is continuously put to use because even after decades of living with the disease, stability is never fully attained; the disease is progressive, chronic complications emerge, life situations change, and the patient is aging.

Collaboratively, diabetes educators and patients address barriers, such as physical, emotional, cognitive, and financial obstacles and develop coping strategies.

Healthy coping: Health status and quality of life are affected by psychological and social factors. Psychological distress directly affects health and indirectly influences a person's motivation to keep their diabetes in control. When motivation is dampened, the commitments required for effective self-care are difficult to maintain. When barriers seem insurmountable, good intentions alone cannot sustain the behavior. Coping becomes difficult and a person's ability to self-manage their diabetes deteriorates.

An important part of the diabetes educator's work is identifying the individual's motivation to change behavior, then helping set achievable behavioral goals and guiding the patient through multiple obstacles. They can provide support by encouraging patients to talk about their concerns and fears and can help them learn what they can control and offer ways for them to cope with what they cannot.

Reducing risks: Effective risk reduction behaviors such as smoking cessation and regular eye, foot, and dental examinations reduce diabetes complications and maximize health and quality of life. An important part of self-care is learning to understand, seek, and regularly obtain an array of preventive services.

Diabetes educators assist patients in gaining knowledge about standards of care, therapeutic goals, and preventive care services to decrease risks. Skills taught include smoking cessation, foot inspections, blood pressure monitoring, self-monitoring of blood glucose, aspirin use, and maintenance of personal care records.

Note: $\odot$ 2009. Reproduced with permission of the American Association of Diabetes Educators. All rights reserved. May not be reproduced or distributed without the written approval of AADE.

Abbreviation: AADE, American Association of Diabetes Educators.

individual's plan may need to include options for what to do if the original plan founders. For example, if the goal is focused on an aspect related to healthy eating, and the individual strays from the plan, there should be a mechanism for how to get back on course. Good plans incorporate available resources, include a variety of strategies, and are sufficiently fluid to reflect relevant change in needs and goals. The best plans are the ones developed by the individual as these are the ones that reflect the person's reality.

Fourth, the plan must be implemented. Implementation may involve collaboration with other professionals and community resources and services. This action step occurs after the DSME encounter. In this step, the individual puts the plan into action. At this stage, the individual is most vulnerable to missteps and failure. During the office visit or educational session, the individual is often highly motivated to achieve his or her goals. After returning home, however, the realities of daily life can interfere with the successful accomplishment of those goals. Beyond setting clear and appropriate goals and having a reasonable plan, having support for selfmanagement can promote success. Ongoing support can be provided in a number of ways and by a variety of providers, but support without initial education is less effective. ${ }^{31}$ The aim of diabetes self-management support is to provide a 
mechanism for assisting the individual to achieve and sustain key self-care behaviors. ${ }^{22,32}$ Support does not replace DSME. It complements and enhances it.

Fifth, evaluation is an essential component of DSME. Thinking about evaluation as the last step is misleading, as it suggests there is finality to the process. There is value in the ongoing evaluation and monitoring for the person with diabetes. As can be seen in Figure 1, the steps in the process of diabetes self-management education reflect a cyclical and ongoing process. Often, the individual's plan will incorporate some level of ongoing monitoring, such as blood glucose levels, exercise logs, or food diaries. Evaluation of these records can take place electronically or telephonically at a frequency that is mutually acceptable to the individual and the clinician. Moreover, evaluation data should comprise at least a portion of the focused assessment that takes place during a return appointment.

The work of the diabetes educator makes use of theories, such as the health belief model, social cognitive theory, and the transtheoretical model. ${ }^{33-35}$ Each theory addresses the complexities of behavior change. With respect to diabetes, this includes the individual's feelings of vulnerability and level of concern about diabetesrelated complications as well as any real or self-imposed environmental factors to be overcome. Notwithstanding these challenges, diabetes educators are successful in using behavior intervention in real-world settings to improve clinical outcomes. The Diabetes Education Accreditation Program is one of two national accreditation bodies for diabetes education programs in the US. In 2012, aggregate

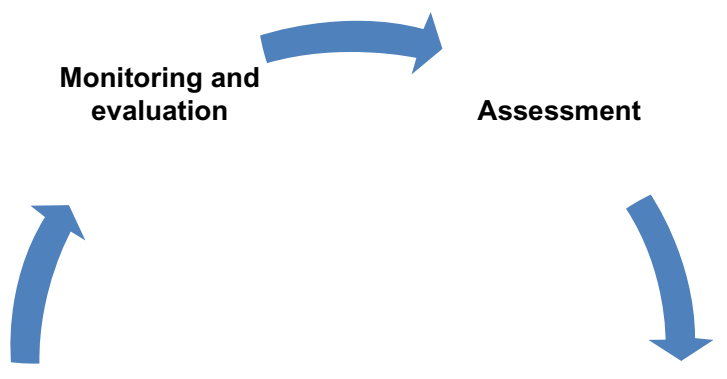

Implementation

Goal setting

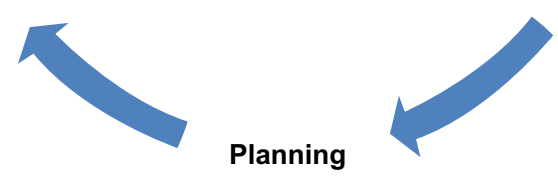

Figure I Steps in the process of diabetes self-management education reflect a cyclical and ongoing process. data from these programs demonstrated a reduction in hemoglobin A1C from 8.39 \pm 0.03 to $7.16 \pm 0.67$ for individuals who completed the DSME program. This $1.23 \%$ reduction $(P=0.0000)$ in $\mathrm{A} 1 \mathrm{C}$ is both statistically significant and clinically meaningful.

DSME should not be an afterthought. The growing body of evidence clearly demonstrates the effectiveness of DSME in improving clinical outcomes ${ }^{36-38}$ and in reducing overall medical costs. ${ }^{39-41}$ Using actuarial data, Duncan et al demonstrated the value of diabetes self-management education in the Medicare population. ${ }^{42}$ Specifically, Duncan et al found that patients receiving diabetes education had lower overall health care costs. And, in a follow-up study, the same investigators found that cost patterns were improved when diabetes education was delivered by diabetes educators in accredited or recognized programs. ${ }^{43}$ Moreover, it became clear that patients participating in episodic DSME were not only more likely to receive guideline-driven care, they were more likely to follow through with treatment recommendations.

DSME is delivered during individual office visits, in group settings, or more commonly, using a hybrid of these modalities. Group education is particularly effective as a means of fostering support, encouragement, and empowerment through the sharing of experiences. Topics vary, according to the individual or collective needs of the group. Diabetes education programs that have achieved recognition (through the American Diabetes Association) or accreditation (through the American Association of Diabetes Educators) are designed and delivered in accordance with established national standards. ${ }^{32}$

\section{Expanding the reach}

More recently, the target of diabetes education has grown to include individuals with prediabetes for the purpose of preventing progression to type 2 diabetes. ${ }^{32,44}$ Prediabetes is a condition of modestly elevated glucose. It can be diagnosed with an oral glucose tolerance test, but it is more commonly diagnosed when fasting blood glucose levels are in the range of $100-125 \mathrm{mg} / \mathrm{dL}(5.6-6.9 \mathrm{mmol} / \mathrm{L})$ and/or hemoglobin A1C values are in the range of $5.7 \%-6.4 \%$. Prediabetes encompasses the conditions of impaired fasting glucose and impaired glucose tolerance and is believed to represent a major risk for the development of type 2 diabetes. ${ }^{3,45}$ The vast majority of the 79 million Americans with prediabetes are unaware they have this condition. ${ }^{1}$ Asymptomatic, this cohort of individuals represents an extremely challenging but critically important group. Unchecked, those with prediabetes can develop both type 2 diabetes and cardiovascular 
disease, swelling the already disproportionately high number of persons with these conditions in the US.

It is clear that the onset of type 2 diabetes can be prevented or significantly delayed, ${ }^{47,49}$ with the most impressive results for doing so coming from lifestyle changes rather than pharmacologic intervention. ${ }^{46-48}$ Lifestyle change is, in essence, behavior change, and behavior change is recognized as the intermediate outcome of diabetes education. Diabetes educators, with their expertise in the realm of behavior change, are the logical providers of diabetes prevention programming for this vulnerable and growing population. ${ }^{50-52}$ Like prediabetes, metabolic syndrome is another high-risk state which includes insulin resistance with or without the presence of glucose intolerance, but it also involves multiple risk factors for cardiovascular disease. These risk factors include abdominal obesity, dyslipidemia, hypertension, proinflammatory, and prothrombotic states. ${ }^{53}$ Although, by definition, metabolic syndrome includes targets for pharmacologic intervention, there is recognition that lifestyle changes are needed to attain weight loss goals. As previously discussed, success in making changes to lifestyle benefits from the type of framework in the elements of self-management education and so - as with prediabetes credentialed diabetes educators are appropriate health care providers to engage.

\section{The diabetes educator}

While certainly in the purview of the diabetes educator, patient education occurs in a number of settings and is delivered by multiple providers. ${ }^{26}$ However, it is important for the reader to appreciate the distinction between patient education and DSME. Both are necessary, but while the former refers to the simple transfer of information, the latter encompasses the complex array of knowledge, skills, and abilities needed to maximize effective self-management. ${ }^{31,54-56}$

Credentialed diabetes educators are health care professionals whose practice focuses on educating individuals with and at risk for diabetes and related conditions to become effective self-managers. Diabetes educators are effective because these skilled clinicians understand the fundamental concept that the vast majority of diabetes care is provided at the individual and the family level. ${ }^{56}$ In addition, the therapeutic alliances they establish with their patients foster respect, empowerment, and shared decision making. ${ }^{55}$ Most commonly, diabetes educators are registered nurses, dietitians, and pharmacists. A wide variety of other clinicians, including nurse practitioners, clinical nurse specialists, physician's assistants, social workers, exercise physiologists, counselors, and others are becoming increasingly more involved in this specialty practice. Beyond academic preparation in their respective disciplines of origin, diabetes educators possess in-depth knowledge and skills derived from the biological and social sciences, communication, counseling, and education. This background, coupled with an extensive knowledge of diabetes management, enables the diabetes educator to concentrate on helping individuals to identify and to achieve self-management goals. These goals, often focused on changing behavior, not only lead to improvements in clinical outcomes, self-management goals also improve problem-solving skills, perception of overall health status, and quality of life.

In the US, there are two specialty practice credentials for diabetes education and/or management specialists. The Certified Diabetes Educator (CDE) credential is open to a wide range of health care professionals who meet or exceed specific criteria set by the National Certifying Board for Diabetes Educators. Some clinicians, who may or may not have the CDE credential, but who possess a master's or higher degree in their professional discipline, choose certification as Board Certified-Advanced Diabetes Managers (BC-ADM). While the focus of the CDE is often limited to diabetes self-management education, the $\mathrm{BC}-\mathrm{ADM}$ is also well-versed in the clinical management of diabetes. Clinical practice at either the CDE or the BC-ADM level is guided by the scope of practice of the individual's discipline of origin and restricted to individual state rules and regulations. Currently, there are nearly 18,000 CDEs and about $750 \mathrm{BC}$ ADMs in the US. ${ }^{57}$ The most common practice setting for diabetes educators is in the hospital outpatient clinics, hospital inpatient settings, or in community-based practices. ${ }^{58}$ The roles of diabetes educators and the settings in which they work are changing and expanding. Because of the diabetes epidemic and its enormous health and economic burden, effective diabetes care and prevention are a growing priority among clinicians and policymakers alike. In a workforce analysis commissioned by the AADE, analysts projected a significant increase in the demand for diabetes educators through 2025. ${ }^{59}$ Given that we live in an era in which the prevalence of diabetes, already at epidemic proportions, is doubling roughly every 15 years, these results were not surprising. What is surprising is that more people are not being referred for diabetes self-management education. Is access the issue? Could it be that providers are working under the mistaken belief that diabetes self-management education does not require a unique skill set? Or, is there an underlying concern that the diabetes educator will somehow interfere with the primary provider's recommendations ${ }^{60-62}$ Whatever the reason for the lack of universal referral, the 
contribution of the credentialed diabetes educator continues to be underutilized.

\section{Summary}

Increasingly, health care is being focused on patient centered outcomes which requires active engagement of both patient and health care provider. Diabetes educators are skilled in the art of collaboration. They engage in it with every patient encounter. Expanding this collaboration throughout the health care team is a natural extension of what educators do on a daily basis. Primary care providers often lack the time needed to effectively engage patients in self-management and would benefit from having access to diabetes education specialists or health coaches. ${ }^{63}$ Aspects of DSME can be provided in a number of ways and by various providers so long as the providers are sufficiently trained and supervised. ${ }^{64-67}$

Diabetes self-management support can be effectively provided by office staff or by peer supporters, but office staff must have sufficient time, and all nonprofessionals must have foundational knowledge and skills. ${ }^{31}$ When self-management support includes DSME provided by a credentialed diabetes educator, the individual is not only more likely to reach and maintain glycemic targets and be satisfied with his or her care, he or she is more likely to feel empowered and experience less diabetes-related distress. ${ }^{31}$

Consumers of health care are increasingly more likely to seek out health care providers who are patient-centered, promote shared decision making, and empower them to be effective self-managers. Credentialed diabetes educators meet all of these expectations.

Access to credentialed diabetes educators has been challenging for providers in rural or other locations not historically served by diabetes education programs. Traditionally, diabetes education has been associated with hospital- or clinic-based practices. Some participants have been lost to follow-up, perhaps because attendance at diabetes education classes was not always accessible or convenient. These days, diabetes educators are increasingly moving into community settings, ${ }^{58}$ participating in shared medical visits or case management, ${ }^{66,68,69}$ taking advantage of opportunities to become embedded in primary care ${ }^{70}$ and/or in Patient-Centered Medical Home practices. ${ }^{71}$ Additionally, diabetes educators are gearing up to meet patient needs for diabetes education and support through the use of information technology. ${ }^{72}$ For all these reasons, diabetes educators are well-positioned to be valuable partners in evolving health care delivery models. Their training and unique focus on individualizing behavioral management and/or change interventions places diabetes educators at the forefront of addressing the needs of patients across a wide spectrum of conditions, including obesity, prediabetes, metabolic syndrome, and diagnosed diabetes.

\section{Disclosure}

SDB is on the speakers bureau for Janssen Pharmaceuticals. DS and RDL have no conflicts of interest to disclose.

\section{References}

1. Centers for Disease Control and Prevention. National diabetes fact sheet: National estimates and general information on diabetes and pre-diabetes in the United States, 2011. In: Services UDoHaH, ed. Atlanta, GA: Centers for Disease Control and Prevention; 2011.

2. Diabetes Atlas [webpage on the Internet]. Brussels: International Diabetes Federation; 2013. Available from: http://www.idf.org/diabetesatlas. Accessed December 19, 2013.

3. American Diabetes Association. Standards of Medical Care in Diabetes - 2013. Diabetes Care. 2013;36(Suppl 1):S11-S66.

4. UK Progressive Diabetes Study (UKPDS) Group. Intensive blood glucose control with sulphonylureas or insulin compared with conventional treatment and risk of complications in patients with type 2 diabetes (UKPDS 33). Lancet. 1998;352(9131):837-853.

5. Pop-Busui R, Herman WH, Feldman EL, et al; DCCT/EDIC Research Group. DCCT and EDIC studies in type 1 diabetes: lessons for diabetic neuropathy regarding metabolic memory and natural history. Curr Diab Rep. 2010;10(4):276-282.

6. The Diabetes Control and Complications Trial Research Group. The effect of intensive treatment of diabetes on the development and progression of long-term complications in insulin-dependent diabetes mellitus. N Engl J Med. 1993;329(14):977-986.

7. Holman RR, Paul SK, Bethel MA, Matthews DR, Neil HA. 10-year follow-up of intensive glucose control in type 2 diabetes. N Engl J Med. 2008;359(15):1577-1589.

8. DCCT/EDIC Research Group, de Boer IH, Sun W, Cleary PA, et al. Intensive diabetes therapy and glomerular filtration rate in type 1 diabetes. N Engl J Med. 2011;365(25):2366-2376.

9. Polak JF, Backlund JY, Cleary PA, et al; DCCT/EDIC Research Group. Progression of carotid artery intima-media thickness during 12 years in the Diabetes Control and Complications Trial/Epidemiology of Diabetes Interventions and Complications (DCCT/EDIC) study. Diabetes. 2011;60(2):607-613.

10. Pop-Busui R, Low PA, Waberski BH, et al; DCCT/EDIC Research Group. Effects of prior intensive insulin therapy on cardiac autonomic nervous system function in type 1 diabetes mellitus: the Diabetes Control and Complications Trial/Epidemiology of Diabetes Interventions and Complications study (DCCT/EDIC). Circulation. 2009;119(22):2886-2893.

11. White NH, Sun W, Cleary PA, et al; DCCT-EDIC Research Group. Effect of prior intensive therapy in type 1 diabetes on 10-year progression of retinopathy in the DCCT/EDIC: comparison of adults and adolescents. Diabetes. 2010;59(5):1244-1253.

12. Marrero DG, Ard J, Delamater AM, et al. Twenty-first century behavioral medicine: a context for empowering clinicians and patients With diabetes: a consensus report. Diabetes Care. 2013;36(2): 463-470.

13. Glasgow RE, Eakin KG. Issues in diabetes self management. In: Shumaker S, Schron E, Ockene J, McBee WL, editors. The Handbook of Health Behavior Change. 2nd ed. New York: Springer; 1998:435-462.

14. Norris SL, Nichols PJ, Caspersen CJ, et al. Increasing diabetes self-management education in community settings: A systematic review. Am J Prev Med. 2002;22(Suppl 4):39-66.

15. Asimakopoulou K, Newton P, Sinclair AJ, Scambler S. Health care professionals' understanding and day-to-day practice of patient empowerment in diabetes; time to pause for thought? Diabetes Res Clin Pract. 2012;95(2):224-229. 
16. Anderson RM, Funnell MM. Patient empowerment: reflections on the challenge of fostering the adoption of a new paradigm. Patient Educ Couns. 2005;57(2):153-157.

17. Funnell MM. Overcoming obstacles: collaboration for change. Eur J Endocrinol. 2004;151 Suppl 2:T19-T22; discussion T29-T30.

18. Committee on Quality of Health Care in America, Institute of Medicine. Crossing the Quality Chasm: A New Health System for the 21st Century. Washington, DC: National Academies Press; 2001.

19. American Association of Diabetes Educators. AADE position statement. Individualization of diabetes self-management education. Diabetes Educ. 2007;33(1):45-49.

20. Inzucchi SE, Bergenstal RM, Buse JB, et al; American Diabetes Association (ADA); European Association for the Study of Diabetes (EASD). Management of hyperglycemia in type 2 diabetes: a patientcentered approach: position statement of the American Diabetes Association (ADA) and the European Association for the Study of Diabetes (EASD). Diabetes Care. 2012;35(6):1364-1379.

21. Ismail-Beigi F, Moghissi E, Tiktin M, Hirsch IB, Inzucchi SE, Genuth S. Individualizing glycemic targets in type 2 diabetes mellitus: implications of recent clinical trials. Ann Intern Med. 2011;154(8):554-559.

22. Kent D, D'Eramo Melkus G, Stuart PM, et al. Reducing the risks of diabetes complications through diabetes self-management education and support. Popul Health Manag. 2013;16(2):74-81.

23. Strine TW, Okoro CA, Chapman DP, Beckles GL, Balluz L, Mokdad AH. The impact of formal diabetes education on the preventive health practices and behaviors of persons with type 2 diabetes. Prev Med. 2005;41(1):79-84.

24. Haas L, Maryniuk M, Beck J, et al; 2012 Standards Revision Task Force. National standards for diabetes self-management education and support. Diabetes Care. 2012;35(11):2393-2401.

25. Mulcahy K, Maryniuk M, Peeples M, et al. Diabetes self-management education core outcomes measures. Diabetes Educ. 2003;29(5):768-770, 773-784, 787-788 passim.

26. Parkin C, Hinnen D, Valentine V, et al. AADE Guidelines for the Practice of Diabetes Self-Management Education/Training (DSME/T). Diabetes Educ. 2009;35:85S-107S.

27. Mulcahy K. Architects of the diabetes team. Diabetes Educ. 1999;25(2): 161-162.

28. Peeples M, Tomky D, Mulcahy K, Peyrot M, Siminerio L; AADE Outcomes Project and AADE/UMPC Diabetes Education Outcomes Project. Evolution of the American Association of Diabetes Educators' diabetes education outcomes project. Diabetes Educ. 2007;33(5): 794-817.

29. Doran GT. There's a SMART way to write management's goals and objectives. Management Review. 1981;70 (AMA FORUM):35-36.

30. Adiseshiah M. Effective care of patients with type 2 diabetes and dyslipidemia: a nurse's perspective. Diabetes Res Clin Pract. 2005; 68 Suppl 2:S23-S27.

31. Siminerio L, Ruppert KM, Gabbay RA. Who can provide diabetes self-management support in primary care? Findings from a randomized controlled trial. Diabetes Educ. 2013;39(5):705-713.

32. Haas L, Maryniuk M, Beck J, et al; 2012 Standards Revision Task Force. National standards for diabetes self-management education and support. Diabetes Care. 2013;36 Suppl 1:S100-S108.

33. Allen NA. Social cognitive theory in diabetes exercise research: an integrative literature review. Diabetes Educ. 2004;30(5):805-819.

34. Glanz K, Rimer BK, Viswanath K. Health Behavior and Health Education: Theory, Research and Practice. 4th ed. New York, NY: John Wiley \& Sons Inc; 2008.

35. Jones H, Edwards L, Vallis TM, et al; Diabetes Stages of Change (DiSC) Study. Changes in diabetes self-care behaviors make a difference in glycemic control: the Diabetes Stages of Change (DiSC) study. Diabetes Care. 2003;26(3):732-737.

36. Deakin T, McShane CE, Cade JE, Williams RD. Group based training for self-management strategies in people with type 2 diabetes mellitus [review]. Cochrane Database Syst Rev. 2005;2:CD003417.
37. Norris SL, Lau J, Smith SJ, Schmid CH, Engelgau MM. Self-management education for adults with type 2 diabetes: a meta-analysis of the effect on glycemic control. Diabetes Care. 2002;25(7):1159-1171.

38. Warsi A, Wang PS, LaValley MP, Avorn J, Solomon DH. Selfmanagement education programs in chronic disease: a systematic review and methodological critique of the literature. Arch Intern Med. 2004;164(15):1641-1649.

39. Boren SA, Fitzner KA, Panhalkar PS, Specker JE. Costs and benefits associated with diabetes education: a review of the literature. Diabetes Educ. 2009;35(1):72-96.

40. Duncan I, Birkmeyer C, Coughlin S, Li QE, Sherr D, Boren S. Assessing the value of diabetes education. Diabetes Educ. 2009;35(5):752-760.

41. Klonoff DC, Schwartz DM. An economic analysis of interventions for diabetes. Diabetes Care. 2000;23(3):390-404.

42. Duncan I, Ahmed T, Li QE, Stetson B, Ruggiero L, Burton K, Rosenthal D, Fitzner K. Assessing the Value of the Diabetes Educator. Diabetes Educ. 2011;37(5):638-657.

43. Duncan I, Ahmed T, Li Q, et al. Assessing the value of the diabetes educator. Diabetes Educ. 2011;37(5):638-657.

44. Sherr D, Lipman RD. Diabetes educators: skilled professionals for improving prediabetes outcomes. Am J Prev Med. 2013;44(4 Suppl 4): S390-S393.

45. Buysschaert M, Bergman M. Definition of prediabetes. Med Clin North Am. 2011;95(2):289-297.

46. Hamman RF, Wing RR, Edelstein SL, et al. Effect of weight loss with lifestyle intervention on risk of diabetes. Diabetes Care. 2006;29(9): 2102-2107.

47. Tuomilehto J, Lindström J, Eriksson JG, et al; Finnish Diabetes Prevention Study Group. Prevention of type 2 diabetes mellitus by changes in lifestyle among subjects with impaired glucose tolerance. N Engl J Med. 2001;344(18):1343-1350.

48. Wing RR, Hamman RF, Bray GA, et al; Diabetes Prevention Program Research Group. Achieving weight and activity goals among diabetes prevention program lifestyle participants. Obes Res. 2004;12(9): 1426-1434.

49. Knowler WC, Barrett-Conner E, Fowler SE, et al; Diabetes Prevention Program Research Group. Reduction in the incidence of type 2 diabetes with lifestyle intervention or metformin. $N$ Engl J Med. 2002;346(6):393-403.

50. Bazata DD, Robinson JG, Fox KM, Grandy S; SHIELD Study Group. Affecting behavior change in individuals with diabetes: findings from the Study to Help Improve Early Evaluation and Management of Risk Factors Leading to Diabetes (SHIELD). Diabetes Educ. 2008;34(6):1025-1036.

51. Green AJ, Bazata DD, Fox KM, Grandy S. Health-related behaviours of people with diabetes and those with cardiometabolic risk factors: results from SHIELD. Int J Clin Pract. 2007;61(11):1791-1797.

52. Fisher EB, Fitzgibbon ML, Glasgow RE, et al. Behavior matters. Am J Prev Med. 2011;40(5):e15-e30.

53. Alberti KG, Eckel RH, Grundy SM, et al; International Diabetes Federation Task Force on Epidemiology and Prevention; Hational Heart, Lung, and Blood Institute; American Heart Association; World Heart Federation; International Atherosclerosis Society; International Association for the Study of Obesity. Harmonizing the metabolic syndrome: a joint interim statement of the International Diabetes Federation Task Force on Epidemiology and Prevention; National Heart, Lung, and Blood Institute; American Heart Association; World Heart Federation; International Atherosclerosis Society; and International Association for the Study of Obesity. Circulation. 2009;120(16):1640-1645.

54. Wilkinson A, Whitehead L. Evolution of the concept of self-care and implications for nurses: a literature review. Int J Nurs Stud. 2009;46(8): 1143-1147.

55. Anderson RM, Funnell MM. The art and science of diabetes education: a culture out of balance. Diabetes Educ. 2008;34(1):109-117.

56. Funnell MM, Tang TS, Anderson RM. From DSME to DSMS: developing empowerment-based diabetes self-management support. Diabetes Spectrum. 2007;20(4):221-226. 
57. D'Souza J, Deshmukh DS, Schreiner B. BC-ADM: What's in it for me and my career. Presented at: American Association of Diabetes Educators 2013 Annual Meeting.

58. Martin AL, Warren JP, Lipman RD. The landscape for diabetes education: results of the 2012 AADE National Diabetes Education Practice Survey. Diabetes Educ. 2013;39(5):614-622.

59. Martin AL, Lipman RD. The future of diabetes education; expanded opportunities and roles for diabetes educators. Diabetes Educ. 2013;39(4):436-446.

60. Hellquist K, Bradley R, Grambart S, Kapustin J, Loch J. Collaborative practice benefits patients: an examination of interprofessional approaches to diabetes care. Health and Interprofessional Practice. 2012;1(2):3.

61. Peyrot M, Rubin RR. Access to diabetes self-management education. Diabetes Educ. 2008;34(1):90-97.

62. Peyrot M, Rubin RR, Funnell MM, Siminerio LM. Access to diabetes self-management education: results of national surveys of patients, educators, and physicians. Diabetes Educ. 2009;35(2):246-248, 252-256, 258-263.

63. Appiah B, Hong Y, Ory MG, et al. Challenges and opportunities for implementing diabetes self-management guidelines. J Am Board Fam Med. 2013;26(1):90-92.

64. Hartman A, Litchman ML, Reed P, Burr RE. In-home chronic disease management in diabetes: a collaborative practice model for home health care and endocrinology providers. Home Health Care Management and Practice. 2009;21(4):246-254.
65. Sewell J, Da Costa S, Dempsey C, et al. Creative partnerships in diabetes nursing: promoting learning through collaborative practice - a preliminary evaluation. European Diabetes Nursing. 2006;3(2):98-101.

66. Wolber T, Ward D. Implementation of a diabetes nurse case management program in a primary care clinic: a process evaluation. J Nurs Healthc Chronic Illn. 2010;2(2):122-134.

67. Zhang JQ, Van Leuven KA, Neidlinger SH. System Barriers Associated With Diabetes Management in Primary Care. J Nurse Pract. 2012;8(10):822-827.

68. Dickman K, Pintz C, Gold K, Kivlahan C. Behavior changes in patients with diabetes and hypertension after experiencing shared medical appointments. J Am Acad Nurse Pract. 2012;24(1):43-51.

69. Burke RE, O'Grady ET. Group visits hold great potential for improving diabetes care and outcomes, but best practices must be developed. Health Aff (Millwood). 2012;31(1):103-109.

70. Siminerio LM, Piatt G, Zgibor JC. Implementing the chronic care model for improvements in diabetes care and education in a rural primary care practice. Diabetes Educ. 2005;31(2):225-234.

71. Gabbay RA, Bailit MH, Mauger DT, Wagner EH, Siminerio L. Mutlipayer patient-cetered medical home implementation guided by the chronic care model. Jt Comm J Qual Patient Saf. 2011;37(6):265-273.

72. Fitzner K, Moss G. Telehealth - an effective delivery method for diabetes self-management education? Popul Health Manag. 2013;16(3): 169-177.

\section{Publish your work in this journal}

Diabetes, Metabolic Syndrome and Obesity: Targets and Therapy is an international, peer-reviewed open-access journal committed to the rapid publication of the latest laboratory and clinical findings in the fields of diabetes, metabolic syndrome and obesity research. Original research, review, case reports, hypothesis formation, expert opinion and commentaries are all considered for publication. The manuscript management system is completely online and includes a very quick and fair peer-review system, which is all easy to use. Visit http://www.dovepress.com/testimonials.php to read real quotes from published authors. 